\title{
Is the Good Cholesterol Bad for Prostate cancer?
}

\author{
Malathi Veeramani ${ }^{1}$, Bioshini Kulothungan ${ }^{2}$, Subramanian Sundaram ${ }^{3}$ \\ ${ }^{1}$ Assistant Professor, Department of Biochemistry, Ethiraj College for Women, Chennai-8,Tamil Nadu,India \\ ${ }^{2}$ Department of Biochemistry, Ethiraj College for Women, Chennai-8,Tamil Nadu,India \\ ${ }^{3}$ Professor in Oncology (Retd), Managing Director, V.S.hospital, Chetpet,Chennai,India
}

\begin{abstract}
The study was carried out to assess the association between HDL Cholesterol levels and Prostate cancer. In the present study the total cholesterol, Triglycerides, LDL, HDL and VLDL in Prostate cancer patients was assayed and compared with the same parameters in normal subjects. The blood lipid levels were assayed by Enzymatic CHOD/ POD method using commerically available assay kits supplied by Beacon Diagnostic Ltd.

A statically significant increase in total cholesterol, Triglycerides, $H D L$ and VLDL was observed. The rise in HDL cholesterol, generally regarded as good cholesterol, seen in prostate cancer samples is a matter of concern. HDL cholesterol influenced tumor proliferation needs to be more researched for better understanding of tumorogenesis in prostate cancer.
\end{abstract}

Key words: Prostate cancer, HDL,LDL,VLDL,Blood lipids

\section{Introduction}

Prostate cancer is the most commonly diagnosed male cancer in the western world [17]. The morbidity and mortality of prostate cancer is significantly higher in western countries than in Asian countries [6]. Little is known about the etiology of Prostate cancer. Like most cancers, both genetic and environmental factors contribute to the pathogenesis of human Prostate cancer. Environment and life style (including diet) are likely to play a more dominant role than inheritance in the development of most Prostate cancer [9].

It has been hypothesized that blood lipid levels might be associated with Prostate cancer risk. Several findings have lead interest in lipid profiles as predictors of Prostate cancer risk [12, 4].Epidemiological studies have described a positive correlation between high serum cholesterol level and prostate aggressiveness $[13,1]$.

Researchers at children hospital Boston have demonstrated that high blood cholesterol levels accelerate the growth of prostate tumors by promoting prostate tumor survival and growth by altering chemical signaling pathways within tumor cells.

Cholesterol plays a central role in steroidogenesis and is a substrate for De novo androgen synthesis and causes irregular growth of prostate cells. Excess intracellular cholesterol is incorporated in to membrane lipid rafts, thereby stabilizing the raft structure and enhancing AKT signaling in prostate cancer cells[2].

Hyper cholesterolemia is believed to contribute to higher serum prostate specific antigen (PSA) and hence to prostate cancer. However the mechanism is not yet understood [5]. In a study by Kok et al., 2011 suggested that blood lipid levels may influence the risk of prostate cancer.

Furthermore the commonly used statins ,Lovastatin, Fluvastatin and Simvastatin , induce apoptosis and inhibit the proliferation of prostate cancer cell lines in culture [18]. A significant chemoprotective effect of statins on prostate cancer has been shown in vivo [16].

\section{Patients}

\section{Materials and methods}

The cancer samples were collected from prostrate cancer patients from V.S hospital , Chetpet , Chennai , India ,after obtaining Institutional ethical clearence and informed consent from the patients to collect the same.The patients were aged between $60-80$ years.

The control group consisted of healthy volunters of similar age group.

\section{Sample Collection}

Randomly 30 Blood samples were collected from patients suffering from prostate cancer . Fasting blood samples were collected in plain vials. Serum was collected after centrifugation .Lipid parameters were measured freshly.

\section{Lipid Profile Studies}

The levels of TG , TC, HDL-Cholesterol and LDL cholesterol were determined by Enzymatic CHOD/ POD method using commerically available assay kits supplied by Beacon Diagnostic Ltd. Tests were 
performed according to the manufacturer's protocol using a semi-autoanalyzer. The concentrations of serum lipid profile were expressed in milligram/ deciliter $(\mathrm{mg} / \mathrm{dl})$

\section{Statistical analysis}

Statistical analyses were carried out using the SPSS satistical software. The results were expressed as mean \pm Standard deviation. The significance of differences between groups was determined by the Student unpaired $t$ test. Values of $p<0.05$ were considered as significant.

\section{Results}

In prostrate cancer samples a statistically significant increase in total cholesterol $(\mathrm{p}=0.023)$, triglycerides $(\mathrm{p}=0.002)$, HDL $(\mathrm{p}=0.005)$ and VLDL $(\mathrm{p}=0.002)$ was observed [ Table :1 ; Graph : 1 ] .

TABLE : 1

\begin{tabular}{|c|c|c|c|c|c|}
\hline & \multicolumn{3}{|c|}{$\begin{array}{l}\text { PROSTRATE CANCER } \\
\end{array}$} & \multirow[b]{2}{*}{ LDL } & \multirow[b]{2}{*}{ VLDL } \\
\hline & CHOLESTEROL & TG & HDL & & \\
\hline $\begin{array}{l}\text { CANCER } \\
\text { PATIENTS }\end{array}$ & $\begin{array}{c}195.44 \\
\pm \\
45.60\end{array}$ & $\begin{array}{c}207.33 \\
\pm \\
67.42\end{array}$ & $\begin{array}{c}53.67 \\
\pm \\
9.14\end{array}$ & $\begin{array}{c}100.56 \\
\pm \\
38.67\end{array}$ & $\begin{array}{c}41.44 \\
\pm \\
13.62\end{array}$ \\
\hline $\begin{array}{l}\text { NORMAL } \\
\text { SUBJECTS }\end{array}$ & $\begin{array}{c}166.11 \\
\pm \\
25.95\end{array}$ & $\begin{array}{c}137.33 \\
\pm \\
59.99\end{array}$ & $\begin{array}{c}45.28 \\
\pm \\
7.57 \\
\end{array}$ & $\begin{array}{c}106.28 \\
\pm \\
27.39\end{array}$ & $\begin{array}{c}27.56 \\
\pm \\
12.11 \\
\end{array}$ \\
\hline$P$ value & 0.023 & 0.002 & 0.005 & 0.611 & 0.002 \\
\hline
\end{tabular}

Lipid profile of prostate cancer patients compared with normal subjects

\section{GRAPH 1 :}

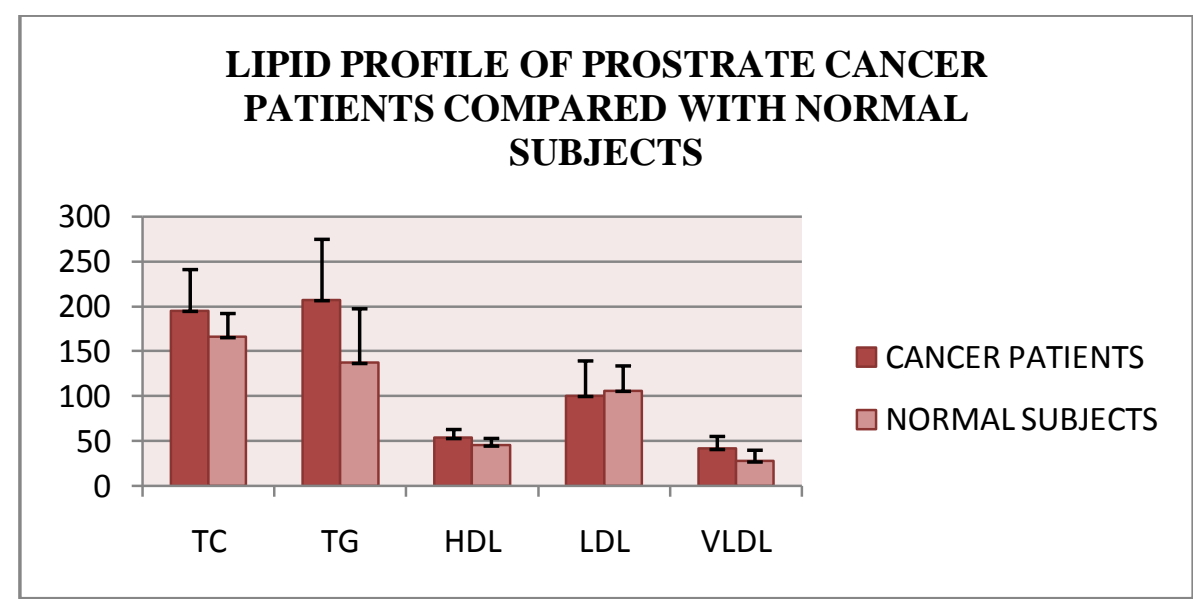

\section{Discussion}

Prostrate cancer is the most common incidental cancer . During the past decade, several findings have led to an augmented interest in lipid profiles as predictors of prostrate cancer risk[4].

It is thought that dietary fat intake might affect prostrate cancer risk . Most population based studies researching on lipids and the risk of prostrate cancer have focused on triglycerides (TG) and total cholesterol (TC) , but very few studies have investigated the role of HDL - cholesterol in patients with prostrate cancer . Kok et al., 2011 reported serum TC, HDL - cholesterol , LDL-cholesterol and TG as potential risk factors for prostrate cancer using multivariable COX proportional hazard regression models . Higher TC and higher LDL cholesterol were significantly associated with an increased risk of prostrate cancer [8].

$\mathrm{HDL}$, which is generally viewed as beneficial, particularly for cardiovascular disease, but the effect of HDL on prostate cancer is unknown[15].

HDL increased serine 727 phosphorylation of STAT 3, but not tyrosine 705 only in DU145 cells. S1P and rHDL-S1P also induced the phosphorylation, but not rHDL without S1P. They also induced DU145 cells migration and invasion ( 14 ). HDL induces the phosphorylation of STAT3 on both tyrosine 705 and serine 727 in ventricular cardio myocytes. [10].

The transcription factor signal transducer and activator of transcription 3 (STAT3) is activated in response to various growth factors, hormones, and cytokines, and has an important role in their signaling .When these ligands bind to the specific transmembrane STAT3 receptor, STAT3 becomes activated by JAK-mediated 
tyrosine phosphorylation of a critical tyrosine residue (Tyr705) and dimerizes through reciprocal Src homology 2-phosphotyrosine interaction. The dimeric STAT3 translocates to the nucleus, where it binds to consensus STAT3 binding sequences within the promoter region of target genes and thereby activates their transcription [3].

In cardiac myocytes HDL and the HDL constituent sphingosine-1-phosphate (S1P) induce a concentration- and time-dependent increase in STAT3 activation. They also enhance extracellular signalregulated kinases (ERK1/2) and p38 mitogen-activated protein kinase (MAPK) phosphorylation[10] .In endothelial cells, HDL suppress apoptosis. This is mediated via S1P3 and subsequent activation of intracellular signaling pathways involving ERK1/2, Akt and eNOS. [11, 7]

Dis regulation and manipulation of the STAT3 signaling pathway is important in tumorigenesis. HDL by an ABCA1-dependent mechanism can mediate signal transduction, leading to increased proliferation and migration of prostate cancer cells.[15].

The results obtained are in accordance with earlier studies .The significant increase in cholesterol levels especially HDL levels would form an important background in prostate cancer prevention.Our results are based on small number of cases $(n=30)$ and require confirmation with increased sample size. Further the exact roles of different cholesterol fractions should also be evaluated.

\section{Conclusion}

Upon comparing the level of total cholesterol, Triglycerides, LDL, HDL and VLDL in Prostate cancer patients with the same parameters in normal subjects a statically significant increase in total cholesterol, Triglycerides, HDL and VLDL was observed. There is positive correlation between high serum cholesterol level especially HDL cholesterol and prostate cancer aggressiveness. Especially the rise in HDL cholesterol, generally regarded as good cholesterol, seen in prostate cancer samples is a matter of concern. This explains the possibility of cholesterol/ cholesterol fractions being a prognostic marker as well as a potential chemotherapeutic target for treating prostate cancer.HDL cholesterol influenced tumor proliferation needs to more researched for better understanding of tumorogenesis in prostate cancer.

\section{Conflicts of Interest}

No potential conflicts of interest were disclosed.

\section{References}

[1]. Batty GD,Kivimaki M,Clarke R, Davey G, Shiplay MJ. Modifiable risk factors for prostate cancer mortality in London; forty years of follow up the white hall study. Cancer causes control .2011: 22;311-8

[2]. Byron H, Margaret G, Pessy R, Jonathan D,Jessica S,Angela H et al.,Dysregulation of cholesterol homeostasis in human prostate cancer: Cancer Research. $2013: 73 ; 1211$

[3]. Darnell JE Jr.STATs and gene regulation. Science 1997; 277:1630-1635

[4]. Dijkman GA, Debruyne FM. Epidemiology of prostate cancer. Eur Urol. 1996;30:281-295

[5]. Godwin O. Ambiguity of plasma cholesterol levels as a biomarker of prostate cancer; Molecular Biomarkers and Diagnosis; 2012; $3 ; 5$.

[6]. Hsing AW,Tsao L,Devesa SS.International trends and patterns prostate cancer incidence and mortality. Int J Cancer ;2000:85:60-7

[7]. Kimura T, Sato K, Kuwabara A, Tomura H, Ishiwara M,Kobayashi I, et al. Sphingosine 1-phosphate may be a major component of plasma lipoproteins responsible for the cytoprotective actions in human umbilical vein endothelial cells. J Biol Chem ;2001; 276:31780-5

[8]. Kok DE, van Roermund JG, Aben KK, den Heijer M, Swinkels DW, Kampman E, et al. Blood lipid levels and prostate cancer risk; a cohort study. Prostate Cancer Prostatic Dis. 2011; 14:340-345.

[9]. Lichtenstein P, Holm NV, Verkasalo PK, Iliadou A, Kaprio J, Koskenvuo M, et al. Environmental and heritable factors in the causation of cancer-analyses of cohorts of twins from Sweden, Denmark, and Finland. N Engl J Med. 2000;13(343):78-85

[10]. Miguel A. Frias, Richard W. James, Christine Gerber-Wicht, and Ursula Lang; Native and reconstituted HDL activate Stat3 in ventricular cardiomyocytes via ERK1/2: Role of sphingosine-1-phosphate Cardiovascular Research .2009; 82, 313-323

[11]. Nofer JR, Levkau B, Wolinska I, Junker R, Fobker M,von Eckardstein A, et al. Suppression of endothelial cell apoptosis by high density lipoproteins (HDL) and HDL-associated lysosphingolipids. J Biol Chem 2001;276:34480-5

[12]. Park S, Bae J, Nam BH, Yoo KY ."Aetiology of cancer in Asia" 2008; Asian Pac. J. Cancer Prev. 9 (3): 371-80.

[13]. Platz EA,Till C, Goodman PJ, Panes H ,Albanes D et al., Men with low serum cholesterol have a lower risk of high grade prostate cancerin the placebo arm of the prostate cancer prevention trial ; Cancer Epidemol Biomarkers Prev.2009;18:2807-13

[14]. Sekine Y, Suzuki K, Remaley AT. HDL and sphingosine-1-phosphate activate stat3 in prostate cancer DU145 cells via ERK1/2 and S1P receptors, and promote cell migration and invasion. Prostate. 2011; 71:690-699.

[15]. Sekine Y, Demosky Sj, Stonik JA, Furuya Y, Kioike H, Suzuki K, Remaley AT.High Density lipoprotein induces proliferation and migration of human prostate androgen-independent cancer cells by an ABCA1-dependant mechanism. Mol Cancer Res. 2010; 8 (9): 1284-94

[16]. Shibata MA,Kavanaugh C,Shiba E ; Comparitive effects of lovastatin on mammary and prostate oncogenesis in transgenic mouse models ; Carcinogenesis.2003; 24(3):453-459

[17]. Sita -Lumsden A, Dart DA, Waxman J: Circulating micro RNAs as potential new biomarker for prostate cancer: British journal of cancer .2013:108, 1925-1930.

[18]. Siva Prasad V, Abbas T, Dutt A ;Differential efficacy of 3-hydroxy-3-methyl glutaryl CoA reductase inhibitors on the cell cycle of prostate cancer cells ; Mol Cancer Ther 2013: 5 (9) ; 2310-2316 